\title{
Investigating the Factors Influencing Parent Toy Purchase Decisions: Reasoning and Consequences
}

\author{
Barween Al Kurdi ${ }^{1}$ \\ ${ }^{1}$ Assistant Professor, Marketing Department, Faculty of Business, Amman Arab University, Amman, Jordan \\ Correspondence: Barween Al Kurdi, Assistant Professor, Marketing Department, Faculty of Business, Amman \\ Arab University, Amman, Jordan.
}

Received: August 26, 2016

doi:10.5539/ibr.v10n4p104

\author{
Accepted: March 13, $2017 \quad$ Online Published: March 23, 2017 \\ URL: https://doi.org/10.5539/ibr.v10n4p104
}

\begin{abstract}
The purpose of this study is to explore and verify the main determinants of parent toy-choice decision-making by using a theoretical model for toy-selection decisions and exploring toy-purchasing behaviour empirically. After reviewing a large number of previous studies, this study's model was developed and designed. A variety of determinants were identified and then categorized into six main broad categories, namely, purpose-of-using related factors, emotional-related factors, educational-related factors, cost-related factors as well as child and parent demographic-related factors. A quantitative methodology was adopted to test the study's model by drawing on six hypotheses, which were then tested statistically. A self-administrative survey was de veloped to collect the preliminary data from customers (mainly parents) who had been involved in toy purchasing by applying the convenience sampling method. The study hypotheses were tested and the findings were also discussed in-depth.

The study found that parent toy purchase decision id derived by a set of factors which are purposes of using-related factors, emotional-related factors, informational-related factors, cost-related factors, children demographical-related factors and parental demographical-related factors.
\end{abstract}

Keywords: toys, parent choice, toy purchase, emotion, education, cost, children demographical factors, parental demographical factors

\section{Introduction}

Parents are often concerned when deciding which toys to buy for their children and for what use or purpose. There has also not been in-depth research on toy-selection determinants in literature. Buying a toy is rather seen as a simple action in its context, but there are a set of considerations behind toy buying that needs to be explored especially from parental perspectives. In addition, toy markets are a complex and changing industry from an economic perspective. For example, the world toy market has been described as dynamic with its sales estimated to be $\$ 61$ billion in 2004 and $\$ 72$ billion in 2007, reaching $\$ 84.1$ billion in 2012 (NDP Group, 2008). In addition, within the US market and according to the Toy Association's report summation, the toy market had reached \$22 billion in 2012 (Toys Industry Association, Inc., 2013).

Choosing a toy is not as simple as the majority of parents may think. A toy should be chosen initially with respect to many child considerations such as abilities, development, safety, age and gender. Howe ver, studies which are related directly to aspects which affect the selecting and purchasing of toys related to educational or emotional aspects are scarce. This finding is evident in spite of some studies referring to the right way of choosing toys for children's use and also recommending careful toy selection by teachers and/or parents. Some of children toy studies have been conducted on toy preferences and toy types as well as toy uniqueness and formation. Thus, this research has been planned to investigate the main factors that determine toy selection in a way to encompass value to the toy purchasing behavioural phenomena, based on new reasoning and consequence classifications, which is seen as important issue today. In addition, providing a practical-based study to practitioners and scholars on how parents usually purchase toys for their children supported by suitable justifications for their decisions, was another considered variable for this study. A further contribution highlighted by this study is that it could help toys producers to explore how parents decide and discern which toy products to purchase for their children in a realistic behavioural setting as well as why these decisions are made. 
From a review of studies, it was found that toy selection research has not been pursued by scholars, and, as a result, there has been limited research conducted to identify the factors affecting toy selection from a parent's point of view, especially in the Jordanian market. When toy purchases are made, three contradictory issues involved with toy requisition are identified, namely, child personality, the reason for the purchases and toy costs (Fisher-Thompson et al., 1995). Also, knowing the reasons behind toy purchases is essential and needs more investigation. However, determining the reasons behind buying are important, other purchase reasoning or unfamiliar purchase consequences that emanate from other sources are also important. These reasons may include TV promotional effects, gender-type effect, fun and learning effect, social interaction effect, parent reference groups, cross-infection and peer friend effects (Angier, 1981; Poulin et al., 1997; Al-dmour \& AlShurideh, 2008; Merriman et al., 2002; Cherney \& London, 2006; Priya et al., 2010; Vail \& Elmore, 2011; AL-Dmour et al., 2014). Moreover, taking a closer look at toy-purchasing influences is important especially when some of these influences play a critical role when buying these products, which are often commensurate to family income, parent education levels and knowing the reasons for buying.

\section{Study Importance}

By reviewing many studies related to toy selection, the toy market is usually influenced by many factors and has faced many challenges. The toy market has been influenced by the increased intention to buy online and the use electronic products, distribution channel changes as the majority of organizations rely on Internet use, rapid product turnover, short life-time cycle and seasonal demand (Johnson, 2001; Bae \& Lee, 2011; Al-dweeri et al., 2017). Such factors influence the process of toys buying and toys buying behaviour. Thus, to understand the vital role in selecting toys, a careful consideration ought to be exerted to know more about toy-product purchasing behaviour by identifying their selection determinants.

The importance of this study is not merely derived from investigating the importance of parental toy selection, but it also comes from having a closer gaze at purchase reasons to determine the relative importance for these reasons. Identifying the main factors that affect parent-toy selection and to what degree these determinants will affect their decision-making leads towards enhancing these behaviours to better understand and subsequently that can be shaped effectively.

The issue statement includes the key problematic factors addressed in a research project. Sekaran (2009, p.45) defines an issue statement as a "clear precise and succinct statement of the specific issue that a researcher wishes to investigate". Based on the literature, this research attempts to provide an understanding of the toy-selection issue and its role in parent toy-selection decisions. In particular, the problem in this research is "to what extent can toy selection determinants be defined and tested within the Jordanian toys market context?" This study addresses this question in a way to facilitate clearly the process of measuring the selected factors and testing their effect on parent toy selection. This study tends to summarize, initially, the main factors affecting toys selection within the parent-behavioural context. Secondly, the study intends to determine the relative importance for each toy selection and purchase determinant from a customer's perspective. Thirdly, it tests statistically a set of factors that have rarely been investigated before, such as educational and emotional interrelated factors that affect parent toy-purchase decisions with respect to child considerations such as age and gender.

\section{Literature Review - Factors Affecting Toy Selection}

By reviewing many studies that relate to toys selection, it has been noted that there are a variety of reasons for selections made. The majority of toy choice studies have been conducted to differentiate initially between boys and girls and have tried to match gender specification and toy selection. A good early toy study example was of toys given to children admitted to hospitals (Gips, 1950). The study found that among the various toy types, children played most frequently with yank toys, fantasy play-type toys, and toys that had parts for handling. Another study revealed some factors which affect the purchase decision of mothers. Children's age is one of the factors; older children make fewer direct attempts to influence the decision of their parents, but they are also more successful with these attempts than the younger children (McNeal, 1969; Ward, 1972; Ward and Wackman, 1972a; Wells, 1965). Further, parents tend to seek opinions from their older children towards the purchases; it was also discovered that with an increase in age, girls begin to make decisions towards products that are both family oriented and for personal use, while boys tend to only purchase products for their own personal agenda (Mehrotra and Torges, 1977). These results contribute to the overall influence mothers have on their daughters in a traditional female role as mothers are the ones who do most of the shopping (McNeal, 1969).

Much of the research on parent toy choice was made on children's toy preferences, which was related to the gender-typing of toys and gender differences in toy selection. According to Goldberg and Lewis (1963) there was a significant gender difference in how much time children of different genders spend with their toys and the 
ways toys were manipulated by young children. Additionally, the effects of the gender of children have on their parents upon toy selection was investigated. The contents of children's rooms as a symbol of parent behaviour was taken into consideration for both genders (Rheingold \& Cook, 1975). In a study by Rheingold and Cook (1975) it was discovered that male infants were provided with more vehicles, educational and art materials, sport equipment, machines and military toys, while female infants were provided with more dolls, doll houses and domestic items. Within the same stream, O'Brien and Huston (1985) noted that more domestic same-gender-type toys that had cross-gender-type toys were possessed by both girls and boys.

A study done on the contents that were found in children's rooms by Rheingold and Cook (1975), found that many of the toys in boys' rooms encouraged them to do outdoors activities, such as sports, cars, animals and the military while girls were directed more towards activities at home like housekeeping and caring for children considering the amounts of babies and dolls. They suggested that this is only due to the behavior of parents and not that of the children themselves as their reasoning was guided by what they found their children enjoyed playing with despite their gender and personality. A study by Eisenberg et al.'s (1985) on parental socialization of young children's toys revealed that parents chose more neutral toys than masculine or feminine toys for their daughters. Another similar study by Schwartz and Markha (1985) on children's toy advertising for gender-stereotyping found that although pictures on toy packages were strongly gender-stereotyped, there was no evidence that parents were influenced by such pictures in their toy selection. While Peretti and Sydney (1984) discovered that both parents and children preferred toys of the same sex and that $91 \%$ of the boys and $81 \%$ of the girls demonstrated a toy preference that related to parental toy choices.

According to O'Brien and Huston (1985), the highest mean ratings to feminine toys for their daughters and to masculine toys for their sons were given by both parents when asked to rate how much they thought their children actually played with a number of toys. When comparing the ratings with the actual proportion of time the children played with their toys, it was revealed that there was a signific ant positive correlation for boys but not for girls. Unlike boys, girls mostly liked to play with blocks, a pegboard, a toy dog and a toy cat, while the boys were more active in their play than were the girls. Unlike girls, Cameron et al. (1985) discovered that boys liked to play more with masculine toys and less with feminine toys. In one study, O'Brien and Huston (1985) found that both boys and girls were considerably more active when playing with stereotyped masculine toys. In another study, O'Brien and Huston (1985) referred to a preference for toys of same gender, which was established by the age of 14 to 20 months in boys and somewhat later in girls. In addition, Jacklin et al. (1973) also found that gender type toy preferences were observable as early as 13 to 14 months.

Fallon and Harris (2001) found that for toy selection parents consider some reasons to be more significant than others. Mostly, studies concentrated on the gender factor. As a result, it was noted that gender was one of the important factors that needed to be taken into consideration because studies focusing on parental toy selection suggested that the gender of the child affected parental toy choice. Freeman (2007) also found that kindergarten kids were able to build-up an understanding of the concept "gender", and he referred to how pre-schoolers modelled behaviour and beliefs. In particular, when it came to toys and playtime, children applied gender stereotypes (Freeman, 2007). However, children often applied gendered play because of parent gender stereotypes and the approval and disapproval of genders for certain toys. Although most research has identified gender as a factor when choosing toys, some research regards gender as less important in toy selection. However, other studies have intensively focused on it as important in toy selection. In addition, it was noted that safety and teaching new talents were also two important reasons for toy selection. The safety factor was uncommonly not mentioned in studies as an important consideration for parents. However, to develop children physically, socially and emotionally, not just food is needed to be chosen with care (Alshurideh, 2014a), toys also must be chosen properly and carefully (Govind et al., 1998). As a result, the most important consideration when purchasing toys was safety then suitability to avoid unexpected accidents (Taylor et al., 1997). Thus, parents, teachers and other professionals should teach children the best way to use specific toy types. In literature, teaching new skills, such as a quality, is important for parents and it is recommended that it should be considered when selecting and buying toys.

Toys are also accompanied with some information and knowledge to consider. This is because toys include information and learning material (for example, printed materials, catalogues, CDs, brochures) to children, and such data helps to teach them self-awareness, language, communication, knowledge, cognitive ability and social skills (Zimmerman \& Calonini, 1971; Alshurideh et al., 2015). However, for Fallon and Harris (2001), information and pictures on toy packages were the least important factors to consider. Martin et al. (1995) also discussed how children used labelling and pictures that were based on gender to determine their preference of toys for themselves and other children. After conducting three experiments with different children, it was 
shown that children used gender-based preferences. For every toy, the children used gender labels and then determined what they preferred and expected what other children would like from it. Therefore, if I were a girl and I liked this particular toy, I would expect that other girls would like it even more than me. While boys, on the other hand, would not like my toy at all. These methods of labelling limited the children's range of learning, creativity and play experience.

Some toy-selection criteria are related to the advertisement factor. Research has found that children's toy advertising and pictures on toy packages were strongly affective on toy selection especially gender-stereotypes (Robertson \& Rossiter, 1976; Curri et al., 2003). Schwartz and Markham (1985) investigated these factors but found there was no evidence that parents were influenced by toy package pictures on their toy selection. Regarding the effect of personality on toys selection, Thompson et al. (1995) studied whether college students selected toys according to personality and requests. Two studies were conducted, the first study was based on gender behaviour and traits to assess toy selection. In the second study, child attitudes were assessed. The study showed that the students selection of toys were consistent with the children's description. It also showed that behaviour traits and attitudes in selecting toys affected their decisions. This was why children, according to the study, who did not request toys, selected their toys according to gender labelling, but children who requested their toys selected more cross-gender toys. In addition, it was found that there were many additional factors that affected toy selection such as novelty and toy categories. Mende (1965) studied the novelty factor and found that there was a positive relationship between toys novelty and children ages. Accordingly, older children, boys and low-anxious children preferred more novelty toys than younger children, girls and high-anxious children. In addition, Gips (1950) studied toys category, novelty and structure in a study about hospitalized children. Gips (1950) found that children who referred to toy category, played mostly with pull toys, imaginary play-type toys and toy-containing manipulation.

Although there have not been many studies focusing on toy selection (Fallon \& Harris, 2001), the majority of studies concentrated on gender and age effect on toy selection (Lam \& Leman, 2003). Both Lam and Leman agreed that either with or without gender labels on toys, children can differentiate between boy and girl toys. Freeman (2007) claimed that children build an understanding of gender during preschools years and they can accurately apply gender stereotypes on toys.

Some scholars such as Caldera et al. (1989) and Campenni (1999) highlighted the effect of parents on children choice and buying behaviour with regard to toy purchases. In addition, there is a vital role for parents in encouraging toy buying that depend on gender when purchasing for their children (Thompson et al., 1995). Based on previous studies, there are about 22 factors influencing toy selection other than gender and these include, safety, teaching skills and creativity, durability and longe vity of use, flexibility and different play uses, physical attractiveness to child, length of time the child pays attention, parent age, parent educational levels, gender of child, age of child, recommendations from another, ethnicity, child requested toys, information on toy package, cost, temporal cost, effort cost, I just like it, novelty, physical attractiveness, picture or advertisement, category and type of toy such as doll, stuffed animal or vehicle (Jacklin et al., 1973; Unger, 1979; Covell, 1981; Christensen and Stockdale, 1991; Chase, 1992; Fisher-Thompson, 1993; Stagnitti et al., 1997; Servin et al., 1999; Fallon and Harris, 2001; Malone and Landers, 2001; Wood et al., 2002). To organise these factors efficiently, they are regrouped into main six categories as explained in the study's framework (see section 4).

\section{Conceptual Framework}

The proposed framework illustrates how certain variables or concepts are connected and correlated to each other. These variables and concepts that frame the majority of models and/or even theories flow logically from the documentation of research conducted to explore problematic areas. An important developing basis for inspecting the research problem is to simultaneously incorporate logical beliefs with published research, taking into consideration the borders and constraints governing the situation. From the theoretical background, a hypothesis which can be subjected to testing, to prove how far a theory is valid (Sekaran, 2009). Thus, the research hypotheses could be proposed according to the research problem and based on the rational premise within an explanation stated through the theoretical framework as illustrated in Figures 1 and 2. 


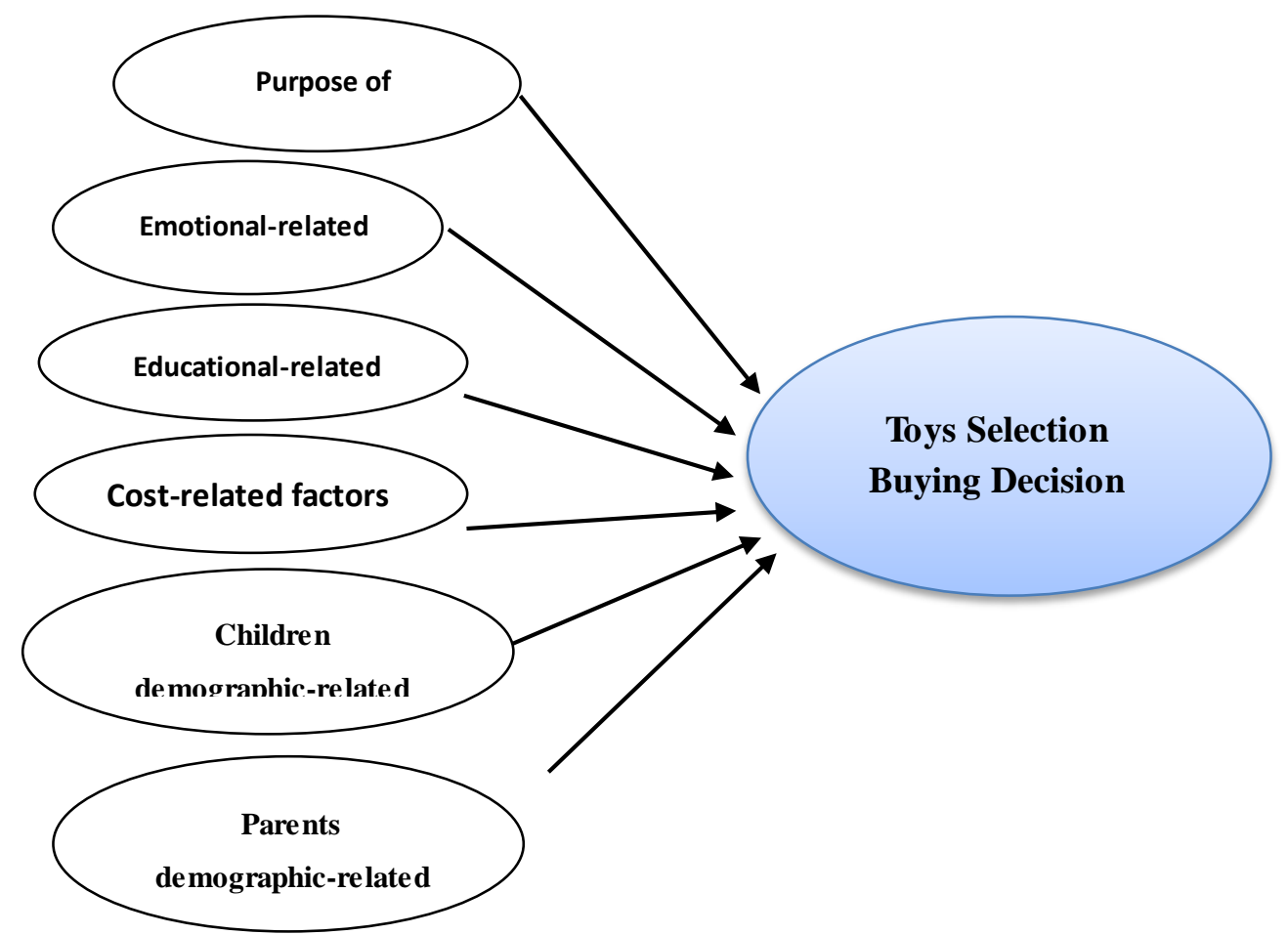

Figure 1. Study Model

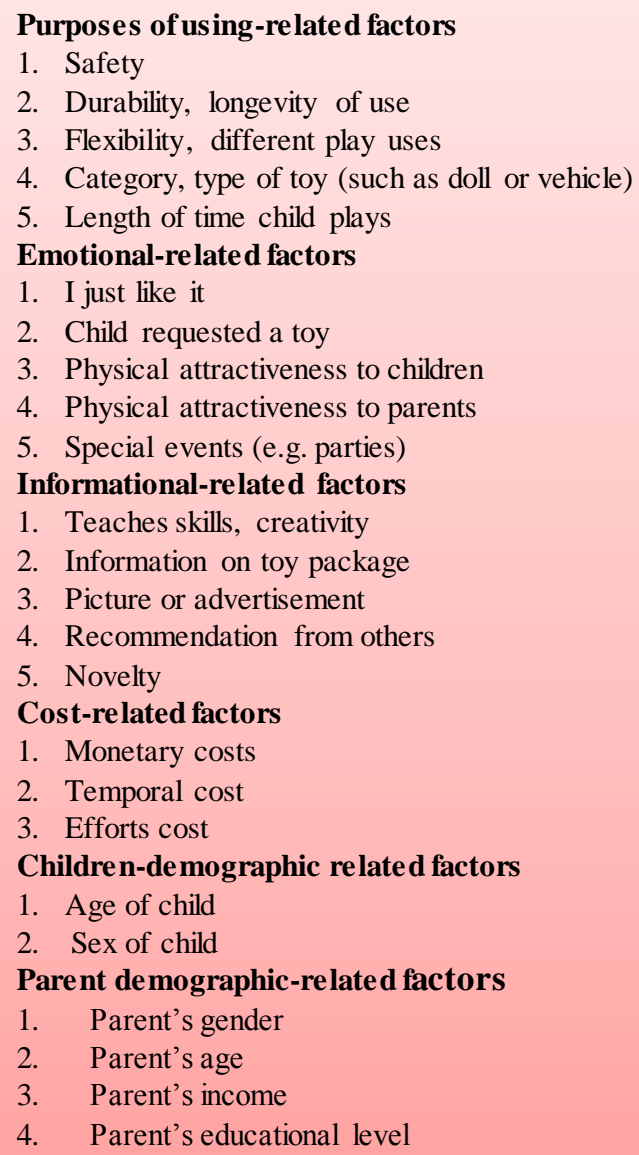

3. Picture or advertisement

4. Recommendation from others

5. Novelty

Cost-related factors

1. Monetary costs

2. Temporal cost

3. Efforts cost

Children-demographic related factors

1. Age of child

2. Sex of child

Parent demographic-related factors

1. Parent's gender

2. Parent's age

3. Parent's income

4. Parent's educational level

Figure 2. Detailed Study Model 


\section{Study Hypotheses}

The study focuses on the effect of toy selection to determine the main toy-choice determinants. The target of this study are parents who take the responsibility of buying these toy products in most cases. By taking a closer look at the study's framework, discussed in section 4, the main hypothesis can be drawn as:

$\mathrm{H} 1$ : Toy selection decisions differed according to purposes of using-related factors

$\mathrm{H} 2$ : Toy selection decisions differed according to emotional-related factors

H3: Toy selection decisions differed according to informational-related factors

H4: Toy selection decisions differed according to cost-related factors

H5: Toy selection decisions differed according to children demographical-related factors

H6: Toy selection decisions differed according to parent demographical-related factors

\section{Study Methodology}

This research has been organized systematically, and the data explored parent choice determinants with the aim of finding an appropriate explanation for toy selection within the Jordanian consumer context. Thus, the main data collection stages should be well-organized to collect empirically-usable data required to test the proposed conceptual model. A quantitative method was adapted to collect the primary data. A special questionnaire was designed and validated to be used as a primary data collection to aid the testing of the study's hypotheses. The study also used secondary data and previous literature to build not just the conceptual framework for the study but also to build the data collection survey items that represented the study's toy-choice factors. This study was conducted in a natural behavioural choice setting, and data was collected from the parents who buy toys using a family as a unit of analysis within the Jordanian market.

Determining the study unit is essential in any study and usually refers to the level of aggregation of the data collected from the study target during the subsequent data analysis stage. Although for Sekaran (2009), a study unit can be individuals, groups, organisations and cultures, for this study, it was the parents or parent who usually bought toy products for themselves or others. The study depended on identifying the sample units from families who visited toys shops using the random sampling method as a non-probability sample. Regarding the response rate, the researcher distributed 550 questionnaires in toys shops located in the capital Amman, Jordan. The number of returned questionnaires that were valid to be analysed was 252 , with a response rate of $44.8 \%$. A Likert scale was used to measure the tendency of respondent views in toy selection using both independent and dependent variables. The Cronbach's Alpha reliability test output for all the study's independent variables showed that the reliability value for the study construct was $80.2 \%$, which was considered very good value compared to other studies within the same context.

\section{Study Analysis}

Regarding the study's descriptive analysis, four main items were tested to give a clear picture of the study sample, namely, gender, age education and income levels.

\subsection{Respondents'Profile}

The analysis showed that more than half of study sample with $56 \%$ of study respondents were males and about $44 \%$ were females. The scale was nominal and the study responses were distributed among four groups according to their ages. Group ' 1 ' refers to the parents who were under the age of (22) years, group ' 2 ' for those who were aged between ( 22 and 30 ) years, group ' 3 ' for those who were aged between ( 31 and 40 ) years, and the last group ' 4 ' for those who were more than (40) years. Results found that approximately $47 \%$ of parents who bought toys between 22 and 30 years of age and more than $27 \%$ of sample were between 31 to 40 years of age.

This indicated that the majority of people who bought toys products were younger and cared about ensuring that their children gained many benefits from using the toy products (for example, entertainment, educational, physical). Regarding the level of education, the results indicated that $78 \%$ of the study sample were educated and had university degrees. This illustrated that educated parents were aware of the benefits of buying toy products that helped in building the child's personality. According to the level of income, results also revealed that more than $42 \%$ of toys purchasers were those whose income was less than 400JD (Jordanian Dinar) and more than 26\% of the study sample's incomes were between $400 \mathrm{JD}$ and $800 \mathrm{JD}$. A notable figure was that the income of $12 \%$ of the study's respondents who bought toy products was more than 1000 JD.

\subsection{Testing the Study Model}

The regression analysis was used to test the study's model, the study constructs relative importance and testing 
of the study hypotheses. Regarding testing the study's model, using the Regression Analysis, the outputs revealed that the model explained about $48 \%$ of the variance of the independent variables while the $\mathrm{R}$ Square was 0.476 and, in total, the independent factors affected parent toy purchase decisions while the Sig value was $0.041 \%$ for the $\mathrm{F}$ value of 4.208 , which was less than $5 \%$.

\subsection{Study Construct's Relative Importance}

The study was planned to find the relative importance of the study factors. The Multiple Regression analysis was employed to measure the relative importance according to Budescu (1993), Johnson (2000) and Alshurideh (2016). As much as the part and partial correlation value(s) increased as much as the construct had more explanatory power than the other independent constructs. This indicated that the higher the part and partial correlation value, the more explanation within the variance of the independent variable. As seen in Table 1, the main factor that affected toys selection was the purposes of using-related factors that ranked first, followed by the educational-related factor as second. However, the demographical-related factors came into the third ranked category followed by the emotional-related factors. One of the notable issues was that the cost-related factors were ranked last which indicated that the toy unit cost was not important compared to the other essential factors such as the educational considerations.

Table 1. Toys selection determinants relative importance and ranks

\begin{tabular}{|c|c|c|c|c|}
\hline \multirow[t]{2}{*}{ Independent Variables } & \multirow{2}{*}{$\begin{array}{l}\text { Mean/ } \\
\text { Average }\end{array}$} & \multicolumn{2}{|c|}{ Correlation } & \multirow{2}{*}{$\begin{array}{c}\text { Relative } \\
\text { importance/Ranks }\end{array}$} \\
\hline & & Partial & Part & \\
\hline Using-related factors & 4.19 & 0.223 & 0.209 & First \\
\hline Emotional-related factors & 3.58 & 0.063 & 0.053 & Sixth \\
\hline Educational-related factors & 4.01 & 0.131 & 0.111 & Forth \\
\hline Cost-related factors & 3.57 & 0.101 & 0.089 & Fifth \\
\hline Child demographical-related factors & 4.06 & 0.190 & 0.167 & Second \\
\hline Parents demographical-related factors & 3.82 & 0.145 & 0.139 & Third \\
\hline
\end{tabular}

As seen in Table 1, the purposes of using-related factor was very important and ranked first and indicated what parents prioritised when choosing and buying toys for their children. This was because the partial correlation value explained of $22.3 \%$ of the variance of parents' choice. This issue was notable as the majority of the parents cared about what consequences could be gained when buying these products, and which included both benefits and even punishments inclusive of the expected risk associated with buying and/or using such products (Al Kurdi, 2016; Alshurideh, 2010). Moreover, while the purchasing power for children increased, it was important to match what to buy with the benefits of the purchasing objects (Acuff \& Reiher, 2008).

In the second tier, children related to demographic-interrelated factors were seen as important from the purchasers' point of view. This was because for the children of the demographical-related factor, the partial correlation value was $19.0 \%$ of the variance in parent choices. This indicated that the purchased object was connected directly to consumer needs and directly to the users' age and gender. Otherwise, no potential benefits might have been gained based on such purchasing. Consequently, parent demographic-related factors were importance and ranked third. This was because for the parents of the demographical-related factor, the partial correlation value was explained at a value of $14.5 \%$ of the variance for parental choice. This indicated that the parent differences were essential when deciding what to buy from the array of toy products and such purchasing might have been different according to the main characteristics such as parent income and level of education. Moreover, the educational-related factors were ranked forth, while the partial correlation value was $13.9 \%$ of the variance in parental choice. This indicated that some parents focused on teaching and learning outcomes that their children were expected to grasp or gain from the purchased object (toys). Alarge number of parents usually procured toys that aided their children in providing educating benefits for different topics such as mathematics, science and even medicine.

The cost-related factors were seen as important for parents and ranked fifth. That was because the cost-related factors partial correlation value was explained at $10.1 \%$ of the variance in parental choice. Prices usually determined what to buy from products/services and even the quality of purchased ones (Girard et al., 2003; Alshurideh, 2014c) especially for economically-minded shoppers (Chen \& Dubinsky, 2003). Having illustrated this, the toy costs were considered essential when determining what to buy for infants and children alike. However, the last factor that was deemed important for parents was the emotional determinants with a low relative importance while such construct explained at a values of $6.3 \%$ of the variance of the parental choice as seen in Table 1 . This factor was related mainly to the social events that usually pushed parents to buy specific toys for special occasions such as birthday parties. 


\subsection{Hypotheses Testing}

\subsubsection{Factor Number One: Purposes of Using-related Factors and Toys Selection}

The purposes of using hypothesis was drawn as:

\section{H1: Toy selection decisions differed according to the purposes of using-related factors}

Using the Hierarchical Multiple Regression (HMR) analysis test, the coefficient Sig value was 0.033 , which was less than $5 \%$. Based on this, it could be noted that there was a statistical significant value proof that toy selection differed according to the purposes of using-related factors. Therefore, the aims of toy purchase varied according to the different purchasing objectives. Some parents expressed special interest in checking if the purchased toy items were not harmful and a child could be safe when using it. On the other hand, toy durability was essential while some high quality toys items were used for a long time and some cheap ones were destroyed after a short time of using. In some cases, some parents care of buying high-quality items to be used by more than one child and for a longer period of time (durability). Keeping in mind that the purpose of toys and their selection process could be considered one of the toy-purchase determinants while some toys were purchased just for entertainment value, while others were chosen to develop skills such as the surgery tool kit toys.

\subsubsection{Factor Number Two: Emotional-related Factors and Toys Selection}

The emotional hypothesis was drawn as:

$\mathrm{H} 2$ : Toys selection decision differed according to emotional-related factors

Using the Hierarchical Multiple Regression (HMR) analysis test, the coefficient Sig value was 0.006, which was less than $5 \%$. Based on this, it was found that there was a statistical significant value proof that toy selection differed according to the emotional-related factors. The emotional factors denoted that parents tended to buy those toy items that the children usually liked and requested. The effect of toy attractiveness was essential while some toys attracted children more than others. Some of children were attracted by toy colour, design, shape and even size. A social pressure (such as a social event) was seen as one of the toy selection determinants. Birthdays, for example, represented the core of toy choices and determined their types such as peers and toy cars.

\subsubsection{Factor Number Three: Informational-related Factors and Toy Selection}

The informational hypothesis was drawn as:

H3: Toys selection decision differed according to informational-related factors

Using the Hierarchical Multiple Regression (HMR) analysis test, the coefficient Sig value was 0.041 , which was less than $5 \%$. Based on this, it was found that there was a statistical significant value proof that toy selection differed according to the informational and educational-related factors.

Some parents chose toys for the educational purposes and to build child creativity such as buying engineering tools. Other parents exerted effort in reading toy labels and usage information. This was because reading such information helped in determining what to choose and buy from a variety of toy types and even assisted in approving the suitability of the toy's use. Some parents also tended to explore the effect of advertisement power on toy selection. This was because the advertisement usually provided a variety of information that supported toy selection such as their usage, price and even availability. Parents tended to read toy package information and user guidance. In addition, it was found that some toys were chosen based on the recommendations of others such as neighbours or a child's peer, friends or relatives. Some toys were chosen because they were new on the market and children had not seen them before. Creativity in toys is a matter of concern for large number of organizations as new and innovative toy types are launched to the market continuously.

\subsubsection{Factor Number Four: Cost-related Factors and Toys Selection}

The cost hypothesis was drawn as:

\section{H4: Toys selection decision differed according to cost-related factors}

Using the Hierarchical Multiple Regression (HMR) analysis test, the coefficient Sig value was 0.032, which was less than 5\%. Based on that, it was found that there was statistical significant value proof that toy selection differed according to the cost-related factors. Cost has been classified by many scholars into many cost factors such as monetary cost, efforts cost and temporal cost. Therefore, cost was important and determined what to buy and choose from the toy market. Some parents allocated a specific amount of money to buy a toy from a local store because of convenience and ease of use. 


\subsubsection{Factor Number Five: Children Demographical-related Factors and Toys Selection}

The children demographical hypothesis was drawn as:

H5: Toys selection decision differed according to children demographical-related factors

Using the HMR analysis test, the coefficient Sig value was 0.033 , which was less than 5\%. Based on that, it was found that there was a statistical significant value proof that toys selection differed according to the children's demographical factors. The main demographical aspects that were taken into consideration in this study were children's age and gender. Most research identifies a relationship between the gender of a child and toy selection, which was supported by this study. The analysis showed that the number of respondents that considered gender to be a very important factor was about $40.0 \%$ of the study sample. On the other hand, the number of respondents who considered gender an unimportant factor was $9.2 \%$, which was in agreement with the findings of Freeman (2007), Okita (2004) as well as Lam and Leman (2003). Thus, toys selection decisions differed according to the children's demographical-related factors.

\subsubsection{Factor Number Six: Parental Demographical-related Factors and Toys Selection}

The parental demographical hypothesis was drawn as:

H6: Toys selection decision differed according to parents demographical-related factors

Using the Hierarchical Multiple Regression (HMR) analysis test, the coefficient Sig value was 0.013 , which was less than 5\%. Based on this, it was found that there was a statistical significant value proof that toy selection differed according to parent demographical factors. This result supported the findings of studies, which found that toy selection was determined by parent gender, age as well as education and income levels. Also, type of toys might not differ but the quality of the toys might. This means that a three-year-old girl a girl might choose a doll but the quality of the doll might differed based on parental income. However, may products' quality or variety be affected (Zu'bi et al., 2012), toy selection would also be influenced by children ages. Toys that would suit a three-year-old girl could differ from that which would suit a five-year-old girl.

\section{Conclusion Remarks}

Based on the study analysis, the results showed that all proposed hypotheses were tested and confirmed that parent selection of toy products differed according to the set of the study's predetermined constructs. These results support the findings of various studies (Fallon \& Harris, 2001; Freeman, 2007; Martin et al., 1995; Lam \& Leman, 2003; Okita, 2004). Also, after researching the relative importance of toy selection determinants and ranking the study's factors, it was noted that the respondents rated two factors as extremely important for toy selection, namely, purposes of using-related factors and children demographical-related considerations. These findings have also been supported by many studies such as Fallon and Harris (2001). Many other elements were found to be important according to the parent perspectives in this study, namely, the safety dimension which needs to be considered and explored in more detail in future research. However, to support children physically, socially and emotionally, toys preferably need to be chosen properly. The most important consideration when purchasing toys is safety, followed by suitability to avoid unexpected accidents (Taylor et al., 1997). In addition, all parties such as parents, teachers and other professionals should cooperate to teach children the best way to use specific types of toys and provide reasons for toy treatment. In addition, teaching new skills using toys was important and recommended by parents when selecting and buying toys. This is because toys, according to Zimmerman and Calonini (1971), could be considered as one of the learning tool materials that help children to teach themselves and enhance different capabilities such as awareness, language, communication, cognitive ability, and even enhances some social skills. Thus, Fallon and Harris (2001) concentrated on the importance of the information and pictures on toy packages as important factors to be considered when teaching children how to operate certain toys to enhance their learnability process.

Most of the previous research that investigated toy purchases concentrated mainly on the influence of child gender on toy selection. However, this study was broader and took into account more diversified factors and variable considerations such as emotional-related factors and purposes of using-related factors. The results of this study were also related to gender considerations, which is supported by other research findings, such as Lam and Leman (2003), Freeman (2007) and Okita (2004). Generally, the parental respondents considered gender in the toy selection process a very important factor, with a value of $40.0 \%$. On the other hand, the parent respondents who considered gender as an unimportant factor was $9.2 \%$.

One of the limitations in conducting this study was the previous lack of research exploring this phenomenon theoretically or practically especially within the Jordanian market. This study might, therefore, provide the chance to study various toy types in relation to family structures and lifestyles in Jordan or to analyse the 
comparative study with different consumer segments within different cultures. Moreover, this study suggests a set of future research avenues. For example, the educational benefits were discussed in-depth and found to affect the parental decision-making process. There is a possibility of these benefits being brought more in line with supported details such as studying toy enhancing specific or specialized skills such as math or knitting skills.

Another issue that could be considered a good avenue to be approached by scholars could be if the purchaser decision were to become voluntary or obligatory and impulsive or planned. Voluntary means that parents purchase a specific toy for their offspring within their own choice-set or to fulfil some of the requirements provisions or criteria such as birthdays or school occasions. Another issue to be considered as a diligent research avenue is the buying of toys based on imitating or copying others. This issue is important owing to some products (for example, toys and sport shows) are usually bought based on the purchase behaviour of others. Thus, copying others or the peer-friend effect is a further research avenue. Children versus parental income is another factor to be researched to investigate if children affect parent toy-purchasing behaviour and vice versa. As brand name and equity are often essential considerations these days, it would be good to explore parental choice for toy products with regard to a set of issues such as brand name, brand choice, parents' experience, marketing ethics, perceived usefulness and perceived enjoyment (Alshurideh et al., 2012; Al Dmour et al., 2014; Alshurideh et al., 2015; Alshurideh, 2016c). This study provides important findings for marketers and practitioners to develop new marketing strategies for selling toy products to consumers and for repeat buying (Alshurideh, 2009; Alshurideh, 2010; Alshurideh et al., 2012; Alshurideh, 2014b; Alshurideh, 2016a, 2016b) by the diversification of the selling of objects especially that relate to different consequences obtained.

\section{References}

Acuff, D., \& Reiher, R. H. (2008). What kids buy: The psychology of marketing to kids. Simon and Schuster.

Al Dmour, H., Alshurideh, M., \& Shishan, F. (2014). The Influence of Mobile Application Quality and Attributes on the Continuance Intention of Mobile Shopping. Life Science Journal, 11(1), 172-181.

AL Kurdi, B. H. (2016). Healthy-Food Choice and Purchasing Behaviour Analysis: An Exploratory Study of Families in the UK. Doctoral thesis, Durham University.

Al-Dmour, H., \& Alshurideh, M. (2008) The Influence of Promotional Mix Elements on Jordanian Consumer's Decision Cell Phone Services Usage: An Analytical Study. The Jordanian Journal of Business Administration, 4(4), 375-392.

AL-Dmour, H., Alshurideh, M., \& Salehih, S. (2014) A Study of Jordanians' Television Viewers Habits. Life Science Journal, 11(6), 161-171.

Al-Duhaish, A., \& Alshurideh, M., Masa'deh, R., \& Alz'bi, Z. (2014). The Impact of the Basic Reference Group Usage on the Purchasing Decision of Clothes (AField Study of Saudi Youth in Riyadh City). Dirasat: Administrative Sciences, 41(2), 205-221.

Al-dweeri, R. M., Obeidat, Z. M., Al-dwiry, M. A., Alshurideh, M. T., \& Alhorani, A. M. (2017). The Impact of E-Service Quality and E-Loyalty on Online Shopping: Moderating Effect of E-Satisfaction and E-Trust. International Journal of Marketing Studies, 9(2), 92-103. https://doi.org/10.5539/ijms.v9n2p92

Alshurideh, M. (2009). A behavior perspective of mobile customer retention: An exploratory study in the UK Market. The End of the Pier? Competing perspectives on the challenges facing business and management. British Academy of Management Brighton-UK. British Academy of Management, 1-19.

Alshurideh, M. (2010). A behavior perspective of mobile customer retention: An exploratory study in the UK Market. The End of the Pier? Competing perspectives on the challenges facing business and management. British Academy of Management Brighton-UK. British Academy of Management, 1-19.

Alshurideh, M. (2010). Customer Service Retention-A Behavioural Perspective of the UK Mobile Market. Doctoral dissertation, Durham University.

Alshurideh, M. (2014b). A Qualitative Analysis of Customer Repeat Purchase Behaviour in the UK Mobile Phone Market. Journal of Management Research, 6(1), 109-125. https://doi.org/10.5296/jmr.v6i1.4659

Alshurideh, M. (2016b). Is Customer Retention Benfitable for Customers: AConceptual Background. Journal of Research in Marketing, 3(3), 368-389.

Alshurideh, M., Masa'deh, R., \& Alkurdi, B. (2012). The effect of Customer Satisfaction upon Customer Retention in the Jordanian Mobile Market: An Empirical Investigation. The European Journal of Economics, Finance and Administrative Sciences, 47, 69-78. 
Alshurideh, M. T. (2014a). Do We Care about What We Buy or Eat? A Practical Study of the Healthy Foods Eaten by Jordanian Youth. International Journal of Business and Management, 9(4), 65-75. https://doi.org/10.5539/ijbm.v9n4p65

Alshurideh, M. T. (2014c). The Factors Predicting Students' Satisfaction with Universities' Healthcare Clinics' Services A Case-Study from the Jordanian Higher Education Sector. Dirasat: Administrative Sciences, 41(2), 451-464. https://doi.org/10.12816/0007482

Alshurideh, M. T. (2016c). Exploring the Main Factors Affecting Consumer Choice of Mobile Phone Service Provider Contracts. International Journal of Communications, Network and System Sciences,9(12), 563.-581.

Alshurideh, M. (2016a). Scope of Customer Retention Problem in the Mobile Phone Sector: A Theoretical Perspective. Journal of Marketing and Consumer Research, 20, March, 64-69.

Alshurideh, M., Al Kurdi, B. H., Vij, A., Obiedat, Z., \& Naser, A. (2016). Marketing Ethics and Relationship Marketing-An Empirical Study that Measure the Effect of Ethics Practices Application on Maintaining $\begin{array}{llll}\text { Relationships with } \quad \text { Customers. International Business } & \text { Research,9(9), }\end{array}$ https://doi.org/10.5539/ibr.v9n9p78

Alshurideh, M., Alhadeed, A. Y., \& Barween, A. (2015). The effect of internal marketing on organizational citizenship behavior an applicable study on the University of Jordan employees. International Journal of Marketing Studies, 7(1), 138-145. https://doi.org/10.5539/ijms.v7n1p138

Alshurideh, M., Bataineh, A., Alkurdi, B., Alasmr, N. (2015). Factors affect Mobile Phone Brand Choices Studying the Case of Jordan Universities Students. International Business Research, 8(3), 141-155. https://doi.org/10.5539/ibr.v8n3p141

Alshurideh, M., Nicholson, M., \& Xiao, S. (2012). The Effect of Previous Experience on Mobile Subscribers' Repeat Purchase Behaviour. European Journal of Social Sciences, 30(3), 366-376.

Angier, N. (1981). Fun and Learning with Science Toys. Discover, 2(12), 46-51.

Bae, S., \& Lee, T. (2011). Gender differences in consumers' perception of online consumer reviews. Electronic Commerce Research, 11(2), 201-214. https://doi.org/10.1007/s10660-010-9072-y

Budescu, D. V. (1993). Dominance analysis: Anew approach to the problem of relative importance of predictors in multiple regression. Psychological Bulletin, 114(3), 542-551. https://doi.org/10.1037/0033-2909.114.3.542

Caldera, Y. M., Huston, A. C., \& O'Brien, M. (1989). Social interactions and play patterns of parents and toddlers with feminine, masculine, and neutral toys. Child development, 70-76. https://doi.org/10.2307/1131072

Cameron, E., Eisenberg, N., \& Tryon, K. (1985). The relation between sex-typed play and pre-schoolers' social behavior. Sex Roles, 12(5/6), 601-615. https://doi.org/10.1007/BF00288180

Campenni, C. E. (1999). Gender stereotyping of children's toys: A comparison of parents and nonparents. Sex Roles, 40(1-2), 121-138. https://doi.org/10.1023/A:1018886518834

Chase, R. A. (1992). Toys and infant development: Biological, psychological, and social factors. Children's Environments, 3-12.

Chen, Z., \& Dubinsky, A. J. (2003). A conceptual model of perceived customer value in e - commerce: A preliminary investigation. Psychology \& Marketing, 20(4), 323-347. https://doi.org/10.1002/mar.10076

Cherney, I. D., \& London, K. (2006). Gender-linked differences in the toys, television shows, computer games, and outdoor activities of 5-to 13-year-old children. Sex Roles, 54(9-10), 717-726. https://doi.org/10.1007/s11199-006-9037-8

Christensen, K. E., \& Stockdale, D. F. (1991). Predictors of toy selection criteria of preschool children's parents. Children's Environments Quarterly, 8(1), 25-36.

Covell, K. (1981). Determinants of exploratory play behaviour of 16-month-old infants: novel toy preferences as a function of experience and complexity (Doctoral dissertation, Simon Fraser University. Theses (Dept. of Psychology).

Curri, T. B., Palmieri, T. L., Aoki, T. H., Kaulkin, C. K., Lunn, M. E., Gregory, C. M., \& Greenhalgh, D. G. (2003). Playing with fire: images of fire on toy packaging. Journal of Burn Care \& Research, 24(3), 


\section{3-165.https://doi.org/10.1097/01.BCR.0000066787.49058.1A}

Eisenberg, N., Wolchik, S., Hernandez, R., \& Pasternack, J. (1985). Parental socialization of young children's play: A short-term longitudinal study. Child Development, 56, 1506-1513. https://doi.org/10.2307/1130469

Fallon, M., \& Harris, M., (2001). Factors influencing the selection of toys for handicapped and normally developing preschool children. Journal of Genetic Psychology, 150(2), 125-134. https://doi.org/10.1080/00221325.1989.9914584

Fisher-Thompson, D. (1993). Adult toy purchases for children: Factors affecting sex-typed toy selection. Journal of Applied Developmental Psychology, 14(3), 385-406. https://doi.org/10.1016/0193-3973(93)90016-O

Fisher-Thompson, D., Sausa, A. D., \& Wright, T. F. (1995). Toy selection for children: Personality and toy request influences. Sex Roles, 33(3-4), 239-255. https://doi.org/10.1007/BF01544613

Freeman, N. (2007). Preschoolers' Perceptions of Gender Appropriate Toy and their Parents' Beliefs About Genderized Behaviors: Miscommunication, Mixed Messages, or Hidden Truths? Childhood Education Journal, 34(5), 357-366. https://doi.org/10.1007/s10643-006-0123-x

Gips, C. (1950). A study of toys for hospitalized children. Child Development, 21(3). 149-161. https://doi.org/10.2307/1125915

Girard, T., Korgaonkar, P., \& Silverblatt, R. (2003). Relationship of type of product, shopping orientations, and demographics with preference for shopping on the Internet. Journal of Business and Psychology, 18(1), 101-120. https://doi.org/10.1023/A:1025087021768

Goldberg, S., \& Lewis, M. (1963). Play behavior in the year-old infant: Early sex differences. Child Development, 40, 21-31.https://doi.org/10.2307/1127152

Govind, N., Wang, Y. A., Da Silva, A. J. R., \& Carter, E. A. (1998). Accurate ab initio energetics of extended systems via explicit correlation embedded in a density functional environment. Chemical physics letters, 295(1), 129-134. https://doi.org/10.1016/S0009-2614(98)00939-7

Jacklin, C. N., Maccoby, E. E., \& Dick, A. E. (1973). Barrier behavior and toy preference: Sex differences (and their absence) in the year-old child. Child Development, 44(1), 196-200. https://doi.org/10.2307/1127703

Johnson, J. W. (2000). A heuristic method for estimating the relative weight of predictor variables in multiple regression. Multivariate behavioral research,35(1), 1-19. https://doi.org/10.1207/S15327906MBR3501_1

Johnson, M. E. (2001). Learning from toys: Lessons in managing supply chain risk from the toy industry. California Management Review, 43(3), 106-124. https://doi.org/10.2307/41166091

Lam, V., \& Leman, P. (2003). The Influence of Gender and Ethnicity on Children's Inferences about Toy Choice. Blackwell Publishing, 9600nGarsington Road, Oxford, UK. https://doi.org/10.1111/1467-9507.00233

Malone, D. M., \& Landers, M. A. (2001). Mothers' perceptions of the toy play of pre-schoolers with intellectual disabilities. International Journal of Disability, Development and Education,48(1), 91-102. https://doi.org/10.1080/10349120120036323

Martin, C., Eisenbud, L., \& Rose, H. (1995). Children's Gender-Based Reasoning. 66(5), 1453-1471. https://doi.org/10.2307/1131657

McLoyd, V. C. (1983). The effects of structure of play objects on the pretend play of low-income preschool children. Child development, 54, 626-635. https://doi.org/10.2307/1130049

Mehrotra, S., \& Torges, S. (1977). Determinants of children's influence on mothers' buying behavior. NA-Advances in Consumer Research, 04, 56-60.

Mendel, G. (1965). Children's preferences for differing degrees of novelty. Child development, 36(1), 453-465. https://doi.org/10.2307/1126468

Merriman, E., Corwin, P., \& Ikram, R. (2002). Toys are a potential source of cross-infection in general practitioners' waiting rooms. Br J Gen Pract, 52(475), 138-140.

NDP Group. (2008) Toys market in the world, 1-19.

O'Brien, M., \& Huston, A. (1985). Activity level and sex-stereotyped toy choice in toddler boys and girls. The Journal of Genetic Psychology, 146(4), 527-533. https://doi.org/10.1080/00221325.1985.10532472

Okita, S. (2004). Effect of age on associating virtual and embodied toys. Cyber Psychology \& Behavior, 7(4), 464-471. https://doi.org/10.1089/cpb.2004.7.464 
Peretti, P., \& Sydney, T. (1984). Parental toy choice stereotyping and its effect on child toy preference and sex role typing. Social Behavior and Personality, 12(2), 213-216. https://doi.org/10.2224/sbp.1984.12.2.213

Poulin, F., Cillessen, A. H., Hubbard, J. A., Coie, J. D., Dodge, K. A., \& Schwartz, D. (1997). Children's friends and behavioral similarity in two social contexts. Social development, 6(2), 224-236. https://doi.org/10.1111/j.1467-9507.1997.tb00103.x

Priya, P., Kanti Baisya, R., \& Sharma, S. (2010). Television advertisements and children's buying behaviour. Marketing Intelligence \& Planning, 28(2), 151-169. https://doi.org/10.1108/02634501011029664

Rheingold, H. L., \& Cook, K. V. (1975). The contents of boys' and girls' rooms as an index of parents' behavior. Child Development, 46, 459-463. https://doi.org/10.2307/1128142

Robertson, T. S., \& Rossiter, J. R. (1976). Short-run advertising effects on children: A field study. Journal of Marketing Research, 13(1), 68-70. https://doi.org/10.2307/3150908

Schwartz, L., and Markham, N. (1985). Sex stereotyping in children's toy advertisement. Sex Roles, 12(1/2), 157-170. https://doi.org/10.1007/BF00288044

Sekaran, U., \& Bougie, R. (2009). Research methods for Business, (5th ed.), John Wiley\& sons Ltd, The Atrium, UK.

Servin, A., Bohlin, G., \& Berlin, L. (1999). Sex differences in 1 - , 3 - , and 5 - year - olds' toy - choice in a structured play - session. Scandinavian Journal of psychology, 40(1), 43-48. https://doi.org/10.1111/1467-9450.00096

Stagnitti, K., Rodger, S., \& Clarke, J. (1997). Determining gender - neutral toys for assessment of preschool children's imaginative play. Australian Occupational Therapy Journal,44(3), 119-131. https://doi.org/10.1111/j.1440-1630.1997.tb00764.x

Thompson, D., Sausa, A., \& Wright, T. (1995). Toy selection for children: Personality and toy request influences. Sex Roles, 33(3), 239-255. https://doi.org/10.1007/BF01544613

Toys Industry Association, Inc. (TIA) (2013). Available online at: http://www.toyassociation.org/TIA/Industry_Facts/salesdata/IndustryFacts/Sales_Data/Sales_Data.aspx\#.Ui cUJ9JHIhG

Unger, R. K. (1979). Toward a redefinition of sex and gender. American Psychologist, 34(11), 1085-1094. https://doi.org/10.1037/0003-066X.34.11.1085

Vail, C. O., \& Elmore, S. R. (2011). Tips for Teachers Selecting Toys to Facilitate Social Interaction. NHSA Dialog, 14(1), 37-40. https://doi.org/10.1080/15240754.2010.541298

Wood, E., Desmarais, S., \& Gugula, S. (2002). The impact of parenting experience on gender stereotyped toy play of children. Sex Roles, 47(1-2), 39-49. https://doi.org/10.1023/A:1020679619728

Zimmerman, L., \& Calovini, G. (1971). Toys as learning materials for preschool children. Syracuse University, Syracuse, New York.

Zu'bi, Z., Al-Lozi, M., Dahiyat, S., Alshurideh, M., \& Al Majali, A. (2012). Examining the effects of quality management practices on product variety. European Journal of Economics, Finance and Administrative Sciences, 51(1), 123-139.

\section{Copyrights}

Copyright for this article is retained by the author(s), with first publication rights granted to the journal.

This is an open-access article distributed under the terms and conditions of the Creative Commons Attribution license (http://creativecommons.org/licenses/by/4.0/). 